\title{
Contextual Integration of Causal Coherence in People with Down Syndrome: Evidence from Figurative Comprehension
}

\author{
Ching-Fen Hsu*
}

\begin{abstract}
Department of Foreign Languages and Literature, Huafan University, 1 Huafan Road, Shiding, Taipei 22301, Taiwan
\end{abstract}

\begin{abstract}
Contextual integration is seldom explored in people with Down syndrome (DS). This study aimed to investigate this ability by comparing causal inferences made by people with DS who were presented with homonyms embedded within sentences and asked to choose which of three interpretations (figurative meaning, literal meaning, or unrelated meaning) was correct. Accuracy was the dependent variable. Each homonym was presented in a scenario familiar to the participants. The results revealed that the participants with DS were the least accurate in responding to figurative meanings and erred most compared to matched controls in chronological age and mental age. It was concluded that people with DS were developmentally delayed in causal inferences and weak central coherence is indeed a syndrome-general phenotype across populations with developmental disorders.
\end{abstract}

Keywords: Down syndrome, causal inference, weak central coherence.

\section{INTRODUCTION}

The integration of contextual information is an important cognitive ability in both verbal and nonverbal domains. Putting contextual cues together and forming a concept to achieve comprehension is termed central coherence [1]. This inferential depth is known as contextual competence [2], which is the ability to integrate parts into a contextual theme using appropriate social knowledge and semantic comprehension. Deficiencies in central coherence or contextual competence have been considered major impairments in people with autism and in righthemisphere damaged patients, resulting in difficulty inferring meanings from expressions and behaving appropriately in social circumstances [3]. Other populations with developmental disabilities such as people with Williams Syndrome (WS) have exhibited weak central coherence performance in both verbal and nonverbal domains, supporting syndrome-general rather than syndrome-specific phenotypes (verbal studies: Hsu et al., 2007 [4]; Hsu, 2013b [5] and nonverbal studies: Grice et al., 2001 [6]; Hsu \& Tzeng, 2011 [7]; Hsu, 2013a, 2013c, 2014b, 2014c [8-11]; Hsu \& Chen, 2014a [12]; Karmiloff-Smith et al., 2004 [13]; Mills et al., 2000) [14]. However, it is not clear whether other populations with genetic deficiencies show delayed or deviant patterns. This study aimed to investigate causal inference in people with Down Syndrome (DS) through figurative comprehension in the context of uncovering their central coherence ability in the verbal domain.

\footnotetext{
*Address correspondence to this author at the Department of Foreign Languages and Literature, Huafan University, 1 Huafan Road, Shiding, Taipei 22301, Taiwan; Tel: +886-2-2663-2102 ext. 3815; Fax: +886-2-2663-2102 ext. 4952; E-mail: chinghsu@cc.hfu.edu.tw
}

People with DS have trisomy of chromosome 21, which was identified in 1959. The condition is associated with serious cognitive and behavioral issues and asynchronies $[15,16]$. Individuals in this clinical population exhibit an uneven profile of superiority on digit span but inferiority on Corsi span, represented as verbal and visuospatial working memory processing [17]. Receptive language is far more severely impaired than nonverbal cognitive ability when measured by the Test for Auditory Comprehension of Language-Revised and the Stanford-Binet Intelligence Scale $\left(4^{\text {th }}\right.$ edition) (Abbeduto et al., p. 10) [18], including grammatical and semantic subtests. Within this uneven profile, the grammatical knowledge (grammatical morphemes, syntactic structures in the passives, relative clauses, interrogatives) of people with DS is poorer than their semantic knowledge (word classes and relations). A test using the Oral and Written Language Scale revealed that the performance of people with DS describing pictures was worse in response to the examiner's verbal prompts, and the expressive language ability of people with DS was poorer than their receptive language ability and nonverbal cognition. In addition, people with DS have been shown to be far more impaired in expressive vocabulary and syntax than people with WS [19].

In the nonverbal domain, standardized first- and second-order false belief tasks have shown that the ability to reason and understand other people's minds is problematic in people with DS [18]. Other visuospatial studies have revealed that visuomotor integration ability using block design tasks in people with DS is not impaired [19]. In contrast to the participants with WS who exhibit local bias without global configuration, participants with DS exhibit the 
reverse pattern. The same finding has been observed in a picture copying task in which DS individuals drew a bicycle and a dog with clear configurations but without disorganized parts, as would be typical for people with WS. In addition, the visuospatial ability of people with DS has been reported as relatively good but with deficiencies. A review of various studies [20] has shown that the ability of people with DS to integrate parts into wholes is relatively weak. Laws and Lawrence (2001) [21], who analyzed the drawings of people with DS, showed that, unlike in typically developing control subjects where there were significant correlations between drawing patterns and language comprehension, verbal mental age, chronological age, and motor skills, these correlations were not observed in people with DS. This suggests a deviant developmental trajectory in spatial representation for this clinical group. The dysmorphology of the brain in people with DS appears to play a role in deficient integration. This verbal-motor laterality of the clinical group has been thought to relate to an impairment of the corpus callosum, which passes cerebral information between hemispheres. Hence, it has been concluded that ability in verbal-motor integration is affected in people with DS. Neurological impairment in the cerebellum, which is related to language development in people with DS, was mentioned in a review of several syndromes such as WS and specific language impairment [22]. Put together, the nonverbal domain of people with DS exhibits weak central coherence. However, there have not been any studies looking at central coherence in the verbal domain from a causal or contextual integration perspective in people with DS. The focus of this study was to investigate causal inference in people with DS to determine central coherence deficits.

\section{METHODS}

\subsection{Participants}

Thirteen people with DS were recruited from several institutes in Taiwan, including the Foundation for Down
Syndrome, the Association for Parents of People with Down Syndrome, and special schools. All of the participants were diagnosed at different ages in hospital as having a gene-specific syndrome related to chromosome 21 and were issued an identification card listed their handicapped category from local city government in Taiwan. A recruitment advertisement was mailed to the individuals through the help of the institutes mentioned. The parents who returned the consent forms were contacted by the researchers to confirm testing dates and locations (home, school, or our institution).

Two separate groups of 13 typically developing (TD) controls were each matched by chronological age (CA) or mental age (MA) and gender based on the full-scale IQ of our clinical individuals. The TD controls were partially the same as the participants who took part in the Hsu study [5] and were students from various high schools in New Taipei City and the Municipal Badou Elementary School with Kindergarten in Keelung. Consent forms with signatures were obtained from the parents or guardians of all of the healthy controls before testing, and all of them were paid for their participation after testing. The backgrounds of the participants are listed in Table 1.

There was no significant age difference between any two groups. The healthy controls in mental age were individually matched based on the full scores of people with DS using the WSIC-IV (Wechsler Scale of Intelligence for Children, fourth edition) [23] for the participants who were under 16 years of age, and the WAIS-III (Wechsler Adult Intelligence Scale, third edition) [24] for those who were older than 16 years. The mean MA of the participants with DS was not significantly different from that of the healthy MA controls $[t(12)=1.02, p=.32]$. The mean CA of the DS group and the healthy $\mathrm{CA}$ controls did not reach significance $[t(12)=1.03, p=.32]$. This study was approved by the Institutional Review Board of the National Cheng Kung University in Taiwan (A-BR-101158 and B-BR-101-079).

Table 1: Participant Age (Standard Deviation) and Gender for the Three Groups

\begin{tabular}{|c|c|c|}
\hline & DS & Controls \\
\hline \hline Chronological age (CA) & $18.15(3.8)$ & $18.88(4.1)$ \\
\hline Age range & $14.05-28.08$ & $14.07-29.04$ \\
\hline Mental age (MA) & $7.8(1.6)$ & $8.38(2.1)$ \\
\cline { 2 - 3 } & $6.03-11.08$ & $5.10-12.02$ \\
\hline Gender ratio (females: males) & $4: 9$ & $4: 9$ \\
\hline
\end{tabular}




\subsection{Materials and Design}

The materials and study design were the same as those used for our study to investigate the causal inference ability of people with WS (Hsu, 2013b, p. 3335) [5], with slight revisions made to meet the recruitment requirements of people with DS for this study. We adapted the methods developed in previous studies of causal inference and central coherence, including the use of the contextual relatedness of inferences [25], backward and forward inferences [26], impaired verbal inferences to physical causality [27], and homograph studies in people with autism spectrum disorders [28]. We combined the notion of semantic priming, which suggests that related pairs should be processed faster or elicit a more accurate response than unrelated pairs, with that of causal inference, which suggests that a successful link between antecedents and consequences can be accessed by selecting context-appropriate meanings. Our previous findings on the semantic knowledge of homonyms of people with WS allowed us to combine these two notions in the causal coherence task conducted in this study. Two causal coherence tasks were tested: backward inference and forward inference. Each task comprised 2 practice trials and 22 experimental trials. As the reading ability of people with DS is limited, all of the trials were presented orally and consisted of situations that were familiar to the clinical individuals and the younger MA-matched participants, such as eating hamburgers or taking exams. The agents in the scenarios were all cartoon characters popular in Taiwan. In the backward inference task, the average length of the homonyms tested was 2.36 syllables ( 14 di-syllabic words and 8 tri-syllabic words), and the average length of the embedded sentences was 30 syllables (range $=17-43$ ). The homonyms were embedded at the end of the last sentence in the causes. The correct answers were distributed across the first (7 times), second (8 times), and third (7 times) choices.

Another 22 scenarios with different homonyms were tested in the forward inference task. The average length of the tested homonyms was 2.40 syllables, and the average length of the embedded sentences was 27 syllables (range $=18-36$ ). The homonyms were embedded at the end of the last sentence in the consequences. The correct answers were distributed as the first ( 7 times), second ( 7 times), and third (8 times) choices, respectively. All of the scenarios were familiar to the participants. The scenarios and the cartoon characters differed from those in the backward inference task. All of the homonyms were very common words in daily conversation in Taiwan. The details of the selection process for the homonyms in each task can be found in Hsu (2013b, p. 3336) [5].

Each trial had an embedded homonym that had a figurative meaning and a literal meaning. The contexts in which the homonyms were embedded were compatible with the figurative meanings. The wordings used in the responses with the figurative meanings did not superficially match the homonyms; however, the literal meanings and unrelated meanings did share syllables. For example, in the homonym 耳邊風, the syllables (Er3 [ear], Bian1 [edge], and Feng1 [wind] in Chinese with tone level) are given as its literal and unrelated meanings. We were interested in investigating whether the individuals with DS would pay more attention to the shared local elements (i.e., the number of syllables) than to integrating the homonym into the preceding context according to its non-literal figurative meaning. Each trial was introduced orally to participants in two parts-cause and consequenceand each trial was presented as a short scenario.

In the backward inference task, the researcher first presented a cause, followed by a consequence. Each cause had a homonym embedded in it. After presenting the two parts, a comprehension question targeting the figurative meaning of the homonym was posed. The participants had to infer the cause of each scenario backwardly from its consequence based on their understanding of the homonym. They were then presented with the figurative, literal, or unrelated meanings of the homonyms and were required to choose the correct alternative. The only way to choose correctly was to successfully make the inference from the consequence to the cause by understanding the homonym. The correct answer bridged the cause and the consequence of each scenario. For example, the cause of the scenario for the backward inference was "Daxung failed the exam this time. His mother often reminded him to study hard, but Daxung was inattentive to his mother's reminders" (original Chinese text: 大雄這次考試不及格, 媽媽平常叫大雄認真讀書, 大雄都把媽媽的話當作耳邊風) and the consequence was "Daxung regretted not paying attention to his mother's reminders" (original Chinese text: 結果是大雄很後悔沒有聽媽媽的話). The comprehension question asked was "What did Daxung do?" (original Chinese text: 請問大雄做了什麼事?) and three alternatives were given for participants to choose from: "Daxung did not take his mother's words seriously" (figurative meaning, original Chinese text: 
大雄不把媽媽的話當作一回事), “There was a wind blowing by Daxung's ears" (literal meaning, original Chinese text: 大雄的耳朵旁吹過一陣風), and “Daxung's ears were itchy because of the blowing wind" (unrelated meaning, original Chinese text: 大雄的耳朵被風吹得很餈).

In the forward inference task, the researcher first introduced a consequence and subsequently its cause. The participants were required to make correct forward inferences from the causes to the consequences. In parallel with the design of the backward inference task, the literal meanings and unrelated meanings shared syllables with the homonyms. For instance, in the homonym 潑冷水 (to dampen one's enthusiasm), the syllables (Po1 [pour], Leng3 [cold], Shuei3 [water]) were included in the alternative literal and unrelated meanings. After posing the test questions, three choices were presented. An example scenario was "Sponge Bob would like to eat the candies on a shelf. $\mathrm{He}$ asked for help from Squidward Tentacles, but Squidward Tentacles dampened Sponge Bob's enthusiasm" (original Chinese text: 海綿寶寶想吃櫃子上的糖果，找章魚哥幫忙， 結果被章魚哥潑冷水); the cause was “It was because Sponge Bob is not tall enough to reach the candies on the shelf' (original Chinese text: 因為海綿寶寶不夠高, 拿不到櫃子上的糖果). The three choices given were "Squidward Tentacles poured cold water on Sponge Bob" (literal meaning, original Chinese text: 章魚哥用冷水潑海綿寶寶), “Squidward Tentacles did not help Sponge Bob to get the candies" (figurative meaning, original Chinese text: 章魚哥沒有幫海綿寶寶拿糖果), and “Sponge Bob likes taking a bath with cold water" (unrelated meaning, original Chinese text: 海綿寶寶喜歡用冷水洗澡).

\subsection{Procedures}

The procedures for the tasks were the same as those used in the previous study (Hsu, 2013b, p. 3336) [5]. The participants were tested in a quiet room at school or at home. To maintain consistency, the researcher first read aloud the trials for the backward inference task and then read the trials for the forward inference task at a normal speed and with a natural intonation (not too rapidly and with no distortion). The researcher did not provide any special hints, inappropriate eye contact, or facial expressions that might have mistakenly guided the participants' responses. Each trial could be repeated once on request. The participants were asked to pay attention to what the researcher said and to circle the correct answers on the answer sheets without help. Before each trial, the participants with DS were asked to recognize the cartoon characters involved from a booklet in which all of the characters were illustrated in color. These visual materials were believed to aid comprehension for the clinical individuals as reported by people with WS in our previous studies [8-10, 12]. Two practice trials were given before the real experiment began to make sure that the people with DS understood the instructions correctly.

\section{RESULTS}

The correct responses to each inference trial in each group were analyzed. The responses to the two inference tasks were taken as the within-subject factor (backward and forward) and groups were the betweensubject factors (CA, MA, and DS). No interaction was found. The correct responses to backward inferences (.80) did not differ from those to forward inferences (.78). The group difference reached significance $[F(2$, 36) $=60.47, p<.001$ ], suggesting that the individuals with DS responded most incorrectly in general among all of the groups [Bonferroni method of comparisons, DS (.51) vs. CA (.99) and DS vs. MA (.86) at $p<.001$ level, CA vs. MA at $p<.03$, standard error $(\mathrm{SE})=.045$ ]. These findings suggest that people with DS were the worst at comprehending causal relationships. The percentage of correct responses is depicted in Figure 1. Overall, the group with DS showed delayed rather than deviant causal inference ability, an index used in this study to represent central coherence ability.

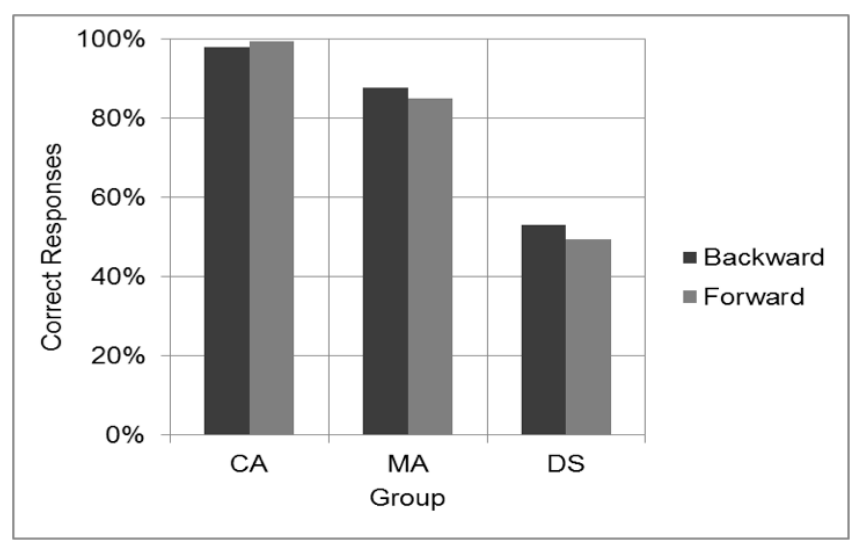

Figure 1: Percentage of correct responses in the three groups of participants in the backward and forward inference tasks.

We were interested to see whether the responses were different among the three types of homonym meanings. Analyses of each type of inference across the groups were thus conducted. For the backward inference analyses, a multivariate analysis of variance 
was conducted taking the percentage of yes responses in the inference types (figurative meaning, literal meaning, and unrelated meaning) as the within-subject factor and the three groups (CA, MA, and DS) as the between-subject factor. The results revealed significant differences in each type (figurative meaning, $F=55.87$, $d f=2,63, p<.001, \eta^{2}=.64$; literal meaning, $F=17.14$, $d f=2,63, p<.001, \eta^{2}=.35$; unrelated meaning, $F=$ 48.24, $d f=2,63, p<.001, \eta^{2}=.61$ ) as shown in Figure 2. Post-hoc analyses using the Bonferroni method showed similar patterns in the backward inference type with the lowest percentage of correct responses from the participants with DS. In all three types of meanings, the participants with DS differed significantly from the MA-matched and CA-matched controls who in turn differed from each other. The results from controls implied adult-like development of backward causal inference takes time from childhood to adulthood. Separate group analyses revealed significant differences among response types in each group [CA, $F(2,42)=2134, p<.001, \eta^{2}=.99 ; \mathrm{MA}, F(2,42)=397, p$ $<.001, \eta^{2}=.97$; DS, $F(2,42)=11.35, p<.001, \eta^{2}=$ .35], suggesting similar patterns across the groups. The percentage of responses of figurative meanings was greater than those of literal meanings and unrelated meanings, although the two latter types of responses did not differ from each other. The responses of the three groups are shown in Figure 2.

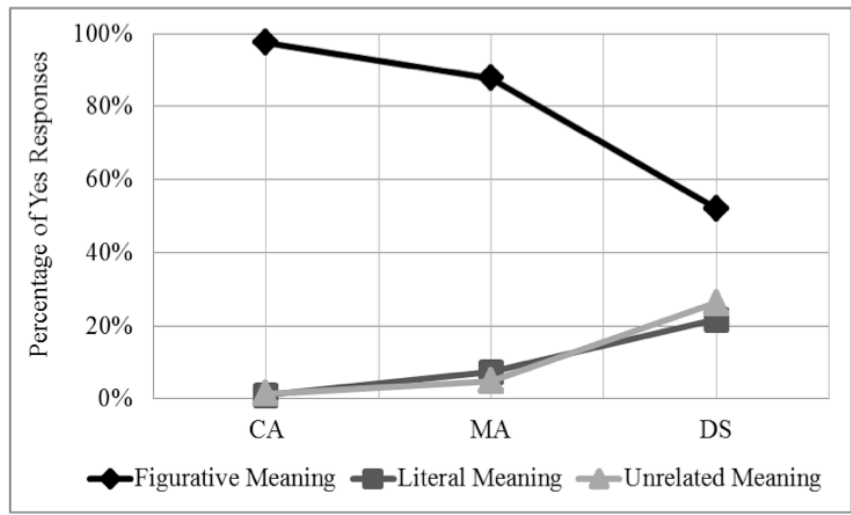

Figure 2: Percentage of yes responses given by each group of participants in the backward inference task.

The analyses of forward inferences used the same method with a within-subject factor and a betweensubject factor in a multivariate analyses of variance. The results revealed significant differences in the responses of each group to each type of inference (figurative meaning, $F=64.21, d f=2,63, p<.001, \eta^{2}=$ .67; literal meaning, $F=21.59, d f=2,63, p<.001, \eta^{2}=$ .41 ; and unrelated meaning, $F=40.83, d f=2,63, p<$ $\left..001, \eta^{2}=.56\right)$. Post-hoc comparisons using the
Bonferroni method suggested that the participants with DS responded least correctly for all inference types. The MA-matched controls gave significantly fewer figurative responses than the CA-matched controls and mistakenly chose more literal responses. No difference was observed in the unrelated responses between these two groups. Responses of the three groups are shown in Figure 3.

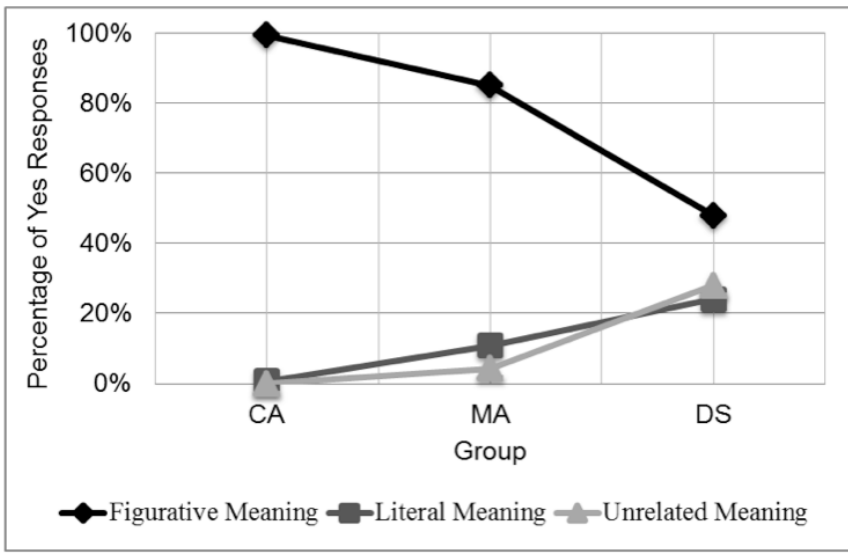

Figure 3: Percentage of yes responses given by each group of participants in the forward inference task.

Separate analyses of each group across inference types showed similar overall patterns [CA, $F(2,42)=$ $6674.33, p<.001, \eta^{2}=.99 ; \mathrm{MA}, F(2,42)=231.30, p<$ $\left..001, \eta^{2}=.92 ; \mathrm{DS}, F(2,42)=6.46, p<.001, \eta^{2}=.24\right]$. Almost all of the participants chose more figurative responses than literal or unrelated responses from the three alternatives. The latter two response types did not reach significance. However, the DS individuals did not show significantly more figurative choices than unrelated responses in forward inferences. No difference in responses was found between literal meanings and unrelated meanings. Based on the findings, it is concluded that for DS people, causal inference ability develops differently in forward and backward directions. Their ability in forward inferences was deviant in contrast to delayed development in backward inferences based on the within-group comparisons for each inference type.

\section{DISCUSSION}

This study aimed to investigate the ability of people with DS to make backward and forward causal inferences to advance understanding of weak central coherence in people with genetic deficits other than the previous study on people with WS [5]. The participants in the study listened to several narrative scenarios, each with a homonym embedded at the end of the story, and they were required to choose the correct 
meaning of the homonym from three options in a comprehension question. The three options included a figurative meaning, a literal meaning, and an unrelated meaning of the embedded homonym. The results of a between-group comparison revealed a distinct pattern of performance in DS individuals who were delayed in both types of inferences. Using the same stimuli, this finding differed from the results observed in $\mathrm{Hsu}$ (2013b) [5] where people with WS performed similarly to their MA-matched controls but differently from their CA-matched controls in both inference tasks. In addition, the performances of both control groups revealed that the ability to make inferences develops over time from childhood into adulthood. The results of a within-group comparison revealed similar performance patterns for each inference type in each group of participants, suggesting substantially slower development of backward causal inferences and probably deviant development of forward inferences in people with DS compared with typically developing (TD) controls. This conclusion is comparable with the performances on false belief tasks observed in people with DS compared with people with fragile $X$ syndrome [18] and individuals with non-specific intelligence deficiency [29], suggesting that poor inference ability might be related to weak theory of mind, which would account for the interpersonal difficulties that people with DS have with peers. Although non-impaired contextual integration ability in people with DS with their mental-matched controls was observed by comparing the learning of new vocabulary in context and out of context [30], our results of the causal relationship in figurative comprehension of central coherence revealed both delayed and deviant processing.

The low percentage of backward and forward causal inferences in people with DS possibly resulted from poor comprehension when listening compared with reading [31]. In the Roch et al.'s study, both the people with DS and the TD controls received the stories through reading and listening followed by multiple options with corresponding pictures. Their pointing responses to each text were measured as dependent variables. The findings revealed that people with DS performed worse in listening comprehension than the TD controls, but the two groups did not differ in reading comprehension. Smith and Jarrold (2014) [32] also demonstrated deviant verbal performance on short-term memory recall in people with DS. Carney et al. (2013) [33] confirmed the poor verbal short-term memory of people with DS in contrast to the poor visuospatial short-term memory of people with WS from developmental between-group comparisons, suggesting a clear double dissociation of verbal and visuospatial short-term memory systems in these two syndromes. Their finding is compatible with our results that people with DS have poor verbal ability. Jarrold, Baddeley, and Phillips (2007) [34] inferred that verbal and visuospatial impairments in people with DS and those with WS represented true deficiencies in shortterm memory subsystems of the phonological loop and visual sketchpad. Hence, these deficits resulted in the general associating impairments in each syndrome. In our study, we used familiar cartoon characters in narrative scenarios to help the understanding of people with DS. Still, our results might be interpreted under the limitations of short-term memory ability in DS individuals. Taken together, these distinct etiologies cause different cognitive functioning profiles in special populations [35]. Our results revealed that figurative comprehension of people with DS showed larger discontinuity to forward and backward inferences, and poorer contextual competence compared to both groups of controls.

These results will be useful for designing intervention programs to improve the cognitive abilities of people with DS. It has been shown that children can make great advances in various cognitive abilities when their weaknesses are strengthened using approaches that take advantage of their natural aptitudes. In a 3-year longitudinal study lacob and Musuroi [36] developed a new program - See and Learn - to introduce three children with DS to new vocabulary and new concepts using pictorial materials and written words. This approach was used because the children, aged 6-8 years, had relatively good visuospatial short-term memory. In addition, through training in strategies to integrate sensory information and express sensory fears, the children gradually managed to deal with various sensory inputs around them and became less sensitive to daily routines. Moreover, with a rehearsing training program (12 sessions, $20 \mathrm{~min}$ each), the DS children increased their memory span for words. This ability was not only observed after training but was also maintained eight months later. lacob and Musuroi also found that the intelligence quotient scores of the children changed. As similar training effects have been demonstrated with computer-assisted programs for people with other developmental disabilities such as autism spectrum disorder [37, 38] and attention deficit hyperactive disorder [39], and neurological disorders such as 
Alzheimer's disease [40-42], it is hoped that similar results can be obtained for people with developmental disabilities. Given this evidence for improvement, we hope that people with DS can eventually attain the same ability to make backward causal inferences and/or to reach non-deviant forward causal inferences as the MA-matched controls after effective training. The educational implication of our study for specialists and parents with children with DS is to teach them by providing more attention to contexts and making connections specifically with figurative or ambiguous words. This training can gradually help people with DS disambiguate words with multiple meanings to reach semantic or pragmatic understanding from contexts.

\section{ACKNOWLEDGEMENTS}

We would like to thank the Taiwanese National Science Council (now Ministry of Science and Technology) for their support (research grant NSC1022410-H-211-001). Our special thanks go to the individuals with Down syndrome and Williams syndrome, and their families, for their support of our studies. We also thank the Down Syndrome Foundation, the Association for Parents of People with Down Syndrome in Keelung, the New Taipei Municipal Special School, and the Taipei School of Special Education.

\section{CONFLICT OF INTERESTS}

The author reports no conflict of interests.

\section{REFERENCES}

[1] Frith U. Autism: Explaining the Enigma. Oxford, UK: Blackwell 1989.

[2] Nerlich B, Clarke DD. Contextual competence: Its growth, use and loss. Studia Anglica Resoviensia: International English Studies Journal, Grzegorz A. Kleparski (Ed.), 1/2002. Rzeszów: Wydawnictwo Uniwersytetu Rzeszowskiego 2002; pp. 64-78.

[3] Brown HH, Michel D, Powelson J, Gardner H. Surprise but not coherence: Sensitivity to verbal humor in righthemisphere patients. Brain and Language 1983; 18: 20-27. http://dx.doi.org/10.1016/0093-934X(83)90002-0

[4] Hsu CF, Karmiloff-Smith A, Tzeng O, Chin RT, Wang HC. Semantic knowledge in Williams syndrome: Insights from comparing behavioural and brain processes in false memory tasks. Proceedings of the 6th IEEE International Conference on Development and Learning 2007; 6: 48-52.

[5] Hsu CF. Contextual integration of causal coherence in people with Williams syndrome. Research in Developmental Disabilities 2013b; 34(10): 3332-3342.

http://dx.doi.org/10.1016/j.ridd.2013.06.031

[6] Grice SJ, Spratling MW, Karmiloff-Smith A, Halit H, Csibra G, de Haan M, Johnson MH. Disordered visual processing and oscillatory brain activity in autism and Williams Syndrome. NeuroReport 2001; 12(12): 2697-2700. http://dx.doi.org/10.1097/00001756-200108280-00021
Hsu CF, Tzeng Ovid JL. Contextual effect in people with Williams syndrome. Research in Developmental Disabilities 2011; 32(2): 781-787.

http://dx.doi.org/10.1016/..ridd.2010.11.001

[8] Hsu CF. Is the contextual effect weak in people with Williams syndrome? An investigation of information integration ability using pictures. Research in Developmental Disabilities 2013a; 34(3): 932-939.

http://dx.doi.org/10.1016/..ridd.2012.11.015

[9] Hsu CF. Cross-modal contextual coherence of semantic integration in people with Williams syndrome. Research in Developmental Disabilities 2013c; 34(12): 4319-4327. http://dx.doi.org/10.1016/j.ridd.2013.09.002

[10] Hsu CF. Modality effect of contextual integration in people with Williams syndrome. Research in Developmental Disabilities 2014b; 35(7): 1571-1578.

http://dx.doi.org/10.1016/j.ridd.2014.03.049

[11] Hsu CF. Cross-domain investigation of weak central coherence in people with Williams syndrome: Asymmetrical brain and behavioral performances in verbal and nonverbal domains. In Porter, O. H. (Ed.), Semantic Memory: Neurobiology, Disorders and Therapeutic Strategies for Improvement, New York: Nova Science Publishers 2014c; pp. 71-82.

[12] Hsu CF, Chen JY. Deviant neural correlates of configural detection in facial processing of people with Williams syndrome. Bulletin of Special Education 2014a; 39(1): 61-84.

[13] Karmiloff-Smith A, Thomas M, Annaz D, Humphreys K, Ewing S, Brace N, van Duuren M, Pike G, Grice S, Campbell R. Exploring the Williams syndrome face-processing debate: the importance of building developmental trajectories. Journal of Child Psychology and Psychiatry 2004; 45(7): 1258-1274. http://dx.doi.org/10.1111/j.1469-7610.2004.00322.x

[14] Mills DL, Alvarez TD, George MS, Appelbaum LG, Bellugi U, Neville H. Electrophysiological Studies of Face Processing in Williams Syndrome. Journal of Cognitive Neuroscience 2000; 12(supplement 1): 47-64. http://dx.doi.org/10.1162/089892900561977

[15] Hickey F, Hickey E, Summar KL. Medical update for children with Down syndrome for the pediatrician and family practitioner. Advances in Pediatrics 2012; 59(1): 137-157. http://dx.doi.org/10.1016/j.yapd.2012.04.006

[16] Rachidi M, Lopes C. Mental retardation and associated neurological dysfunctions in Down syndrome: A consequence of dysregulation in critical chromosome 21 genes and associated molecular pathways. European Journal of Paediatric Neurology 2008; 12: 168-182.

http://dx.doi.org/10.1016/j.ejpn.2007.08.010

[17] Jarrold C, Baddeley AD. Short-term memory for verbal and visuospatial information in Down's syndrome. Cognitive Neuropsychiatry 1997; 2(2): 101-122. http://dx.doi.org/10.1080/135468097396351

[18] Abbeduto L, Pavetto M, Kesin E, Weissman MD, Karadottir $\mathrm{S}$, O'Brien A, Cawthon S. The linguistic and cognitive profile of Down syndrome: Evidence from a comparison with fragile $X$ syndrome. Down Syndrome Research and Practice 2001; $7(1): 9-15$

http://dx.doi.org/10.3104/reports.109

[19] Bellugi U, Lichtenberger L, Jones W, Lai Z, George M. The neurocognitive profile of Williams syndrome: A complex pattern of strengths and weaknesses. Journal of Cognitive Neuroscience 2000; 12: 7-29. http://dx.doi.org/10.1162/089892900561959

[20] Yang YY, Conners FA, Merrill EC. Visuo-spatial ability in individuals with Down syndrome: Is it really a strength? Research in Developmental Disabilities 2014; 35: 1473-1500. http://dx.doi.org/10.1016/j.ridd.2014.04.002 
[21] Laws G, Lawrence L. Spatial representation in the drawings of children with Down's syndrome and its relationship to language and motor development: A preliminary investigation. British Journal of Developmental Psychology 2001; 19: 453-473.

http://dx.doi.org/10.1348/026151001166119

[22] Ypsilanti A, Grouios G. Linguistic profile of individuals with Down syndrome: Comparing the linguistic performance of three developmental disorders. Child Neuropsychology 2008; 14: $148-170$. http://dx.doi.org/10.1080/09297040701632209

[23] Chen $\mathrm{RH}$, Chen CY. Wechsler Scale Intelligence Test for Children (4th ed.). Taipei: Bookstore for Chinese Behavioral Science (Chinese version) 2010.

[24] Chen RH, Chen CY. Wechsler Adult Intelligence Scale (3rd ed.). Taipei: Bookstore for Chinese Behavioral Science (Chinese version) 2002.

[25] Kuperberg GR, Paczynski M, Ditman T. Establishing causal coherence across sentences: An ERP study. Journal of Cognitive Neuroscience 2011; 23(5): 1230-1246. http://dx.doi.org/10.1162/jocn.2010.21452

[26] Singer M, Ferreira F. Inferring consequences in story comprehension. Journal of Verbal Learning and Verbal Behavior 1983; 22: 437-448. http://dx.doi.org/10.1016/S0022-5371(83)90282-7

[27] Santos A, Deruelle C. Verbal peaks and visual valleys in theory of mind ability in Williams syndrome. Journal of Autism and Developmental Disorders 2009; 39: 651-659. http://dx.doi.org/10.1007/s10803-008-0669-0

[28] Happé FGE. Central coherence and theory of mind in autism: Reading homographs in context. British Journal of Developmental Psychology 1997; 15(1): 1-12. http://dx.doi.org/10.1111/j.2044-835X.1997.tb00721.x

[29] Giaouri S, Alevriadou A. Second-order false belief attribution in children with non-specific intellectual disabilities and Down syndrome: Social-cognitive profile research and educational planning challenges. Bulletin of the University of Ploesti, Educational Series 2010; 62(2).

[30] Roch M, Florit E, Levorato C. The role of linguistic context in deriving word meanings in individuals with Down Syndrome. Research in Developmental Disabilities 2013; 34: 605-615. http://dx.doi.org/10.1016/j.ridd.2012.09.014

[31] Roch M, Florit E, Levorato $\mathrm{C}$. The advantage of reading over listening text comprehension in Down syndrome: What is the role of verbal memory? Research in Developmental Disabilities 2012; 33: 890-899. http://dx.doi.org/10.1016/j.ridd.2011.11.002

[32] Smith E, Jarrold C. Grouping, semantic relation and imagery effects in individuals with Down syndrome. Research in Developmental Disabilities 2014; 35: 3162-3174. http://dx.doi.org/10.1016/j.ridd.2014.07.061
[33] Carney DPJ, Henry LA, Messer DJ, Danielsson H, Brown JH, Ronnberg J. Using developmental trajectories to examine verbal and visuospatial short-term memory development in children and adolescents with Williams and Down syndromes. Research in Developmental Disabilities 2013; 34: 3421-3432.

\section{http://dx.doi.org/10.1016/j.ridd.2013.07.012}

[34] Jarrold C, Baddeley AD, Phillips C. Long-term memory for verbal and visual information in Down syndrome and Williams syndrome: Performance on the doors and people test. Cortex 2007; 43: 233-247. http://dx.doi.org/10.1016/S0010-9452(08)70478-7

[35] Powell L, Houghton S, Douglas G. Comparison of etiologyspecific cognitive functioning profiles for individuals with fragile $X$ and individuals with Down syndrome. Journal of Special Education 1997; 31(3): 362-376. http://dx.doi.org/10.1177/002246699703100305

[36] lacob I, Musuroi C. Aspects of adapting the intervention program to the particular learning profile of children with Down syndrome. Procedia-Social and Behavioral Sciences 2013; 84: 846-849. http://dx.doi.org/10.1016/j.sbspro.2013.06.659

[37] Golan O, Baron-Cohen S. Systemizing empathy: Teaching adults with Asperger syndrome or high-functioning autism to recognize complex emotions using interactive multimedia. Development and Psychopathology 2006; 18: 591-617. http://dx.doi.org/10.1017/S0954579406060305

[38] Wainer AL, Ingersoll BR. The use of innovative computer technology for teaching social communication to individuals with autism spectrum disorders. Reach in Autism Spectrum Disorders 2011; 5: 96-107. http://dx.doi.org/10.1016/j.rasd.2010.08.002

[39] Chuang TY, Lee IC, Chen WC. Use of Digital console game for children with attention deficit hyperactivity disorder. USChina Education Review 2010; 7(11): 99-105.

[40] Barnes DE, Yaffe K, Belfor N, Jagust WJ, DeCarli C, Reed $\mathrm{BR}$, Kramer JH. Computer-based cognitive training for mild cognitive impairment: Results from a pilot randomized, controlled trial. Alzheimer Disease and Associated Disorders 2009; 23(3): 205-210. http://dx.doi.org/10.1097/WAD.0b013e31819c6137

[41] Cipriani G, Bianchetti A, Trabucchim M. Outcomes of a computer-based cognitive rehabilitation program on Alzheimer's disease patients compared with those on patients affected by mild cognitive impairment. Archives of Gerontology and Geriatrics 2006; 43: 327-335. http://dx.doi.org/10.1016/j.archger.2005.12.003

[42] Lee GY, Yip C, Yu E, Man D. Evaluation of a computerassisted errorless learning-based memory training program for patients with early Alzheimer's disease in Hong Kong: A pilot study. Clinical Interventions in Aging 2013; 8: 623-633. 